\title{
Unequal benefits - diverging attitudes? Analysing the effects of an unequal expansion of childcare provision on attitudes towards maternal employment across 18 European countries
}

\author{
Erik Neimanns*(iD) \\ Max Planck Institute for the Study of Societies, Cologne, Germany \\ ${ }^{\star}$ Corresponding author. E-mail: Neimanns@mpifg.de
}

(Received 23 November 2018; revised 8 November 2019; accepted 25 November 2019; first published online 07 January 2020)

\begin{abstract}
Childcare policies have become an important element of social investment reforms, but in most countries access to childcare has remained socially unequal. Some studies have suggested that a trend towards more gender egalitarian work-family attitudes has facilitated the expansion of childcare provision. Yet, we know little about the repercussions of an unequal expansion of childcare provision on public attitudes towards the work-family nexus. Building on multilevel models of 18 European countries and two waves of the International Social Survey Programme, this analysis examines the effects of an unequal childcare expansion on attitudes towards maternal employment. The results reveal that individuals with lower income remain more skeptical of maternal employment when childcare provision is highly unequal. The unequally distributed benefits of an expansion of childcare provision contribute to a divergence of attitudes across socio-economic groups, which might create a more difficult political terrain for the implementation of expansive social investment reforms.
\end{abstract}

Keywords early childhood education and care; gender role attitudes; maternal employment; policy feedback; public attitudes; social investment

\section{Introduction}

Over recent years, childcare policies have received a great deal of attention as a central element of the emerging paradigm of a social investment welfare state (Morel et al. 2012; Garritzmann et al. 2017; Hemerijck 2013, 2017). The expectation is that childcare services will mitigate social inequalities over the life course by contributing to social and cognitive child development and by facilitating the combination of work and family life (e.g. Esping-Andersen 2002). Some European countries have considerably expanded childcare provision, following the Barcelona targets agreed upon in 2002 by

(c) The Author(s) 2020. This is an Open Access article, distributed under the terms of the Creative Commons Attribution licence (http://creativecommons.org/licenses/by/4.0/), which permits unrestricted re-use, distribution, and reproduction in any medium, provided the original work is properly cited. 
the European Union member states, which aimed to increase childcare enrolment rates for children under the age of three to at least 33\% by 2010 (Hemerijck 2013). However, substantial variation across countries persists in approaches to childcare provision and in the degree to which childcare is accessible for parents from different socio-economic backgrounds. In most countries, access remains limited due to insufficient levels of coverage or high levels of private fees that parents have to pay (Van Lancker 2013, 2018; Abrassart and Bonoli 2015). Given such crossnational differences in the design of childcare policies, the underlying political support structure of expansive childcare reforms is still poorly understood. Some analyses emphasise that attitudes have become more supportive of maternal employment and dual-earner arrangements over time, which has spurred electoral competition between political parties to enact workfriendly family policies (Morgan 2013; Hemerijck 2015; Blome 2017; Schwander 2018). Yet, we still lack understanding of why this change in attitudes has been more pronounced in some countries than in others.

A substantive body of work has studied the determinants of work-family attitudes under the different labels of gender role attitudes, gender ideology or attitudes towards maternal and female employment to explain attitude trends and variation in attitudes within and across countries (e.g. Knudsen and Wærness 2001; Bolzendahl and Myers 2004; Davis and Greenstein 2009). In general, this research finds that attitudes have become more egalitarian and supportive of maternal employment over time, but substantial unexplained variation remains across countries. In some countries, change has occurred rather slowly and in others there has been a reversal of the trend for attitudes to become more egalitarian (Braun and Scott 2009). More recently, analyses using single-country panel studies have shown how family policies aiming at facilitating the combination of work and family life contribute to attitudes becoming more gender egalitarian (e.g. Zoch and Schober 2018). While such an approach is highly insightful in identifying the effects of policy change on attitude change, a limitation is that it does not allow examining to what extent variation in the institutional design of childcare provision accounts for variation in attitude trends towards maternal employment across countries.

Building on an extensive literature on policy feedback effects (Sjöberg 2004; Kumlin and Stadelmann-Steffen 2014; Gangl and Ziefle 2015; Zoch and Schober 2018), I argue that the country-specific institutional characteristics of childcare provision crucially condition the effects of an expansion of childcare provision on attitudes towards maternal employment. More specifically, I examine how the generosity of public spending on childcare provision and the inherent degree of social inequality in childcare enrolment shape attitudes of different socio-economic groups over time regarding the paid employment of mothers with small children. Because, on average, mothers are still more likely to be the primary caregiver in the household, an expansion of childcare provision should affect mothers' take up of paid employment in particular, as well as public attitudes related to the issue of maternal employment. In line with existing literature (Sjöberg 2004; Zoch and Schober 2018), I expect an expansion of childcare to lead to attitudes becoming more supportive of maternal employment because it makes it easier for mothers to combine work and family life. On the one hand, childcare provision affects families' cost-benefit calculations on combining work and family life which should translate into attitudes towards maternal employment according to a logic of 
material self-interest. On the other hand, childcare provision alters individual exposure to certain norms and ideas of what is socially considered as appropriate behaviour for parents. I add to this literature by making explicit the crucial role of inequality in access to childcare, which I understand throughout this article as the degree to which higher-income parents are overrepresented compared to lower-income parents among the users of childcare. Where access to childcare is unequal, generous public spending on childcare services should contribute less to the evolution of more gender egalitarian attitudes towards working mothers. The conditioning effect of inequality should be particularly pronounced for individuals with lower incomes because those individuals hardly benefit from expanded, but unequal childcare provision. The empirical findings provide support for the line of reasoning elaborated in this article. The results imply that an expansion of childcare which does not address existing inequalities in access to care is likely to lead to attitudes towards maternal employment diverging across socio-economic groups and it runs the risk of reducing the legitimacy of reforms aimed exactly at improving the reconciliation of work and family life.

The next section discusses how work on the determinants of attitudes towards maternal employment insufficiently takes into account the institutional realities of childcare provision and develops a theoretical framework to account for the effects of unequal childcare provision on attitudes across socio-economic groups. The empirical section puts these propositions to the test. I use data from two waves of the International Social Survey Programme on gender role attitudes (ISSP 2002, 2012), from the Organisation for Economic Co-operation and Development (OECD) on public childcare spending (OECD 2017), and Van Lancker's (2018) data on income inequality in childcare enrolment to estimate multilevel regression models over time for a sample of 18 European countries. A final section summarises the findings and highlights the implications for the politics of expanding childcare.

\section{Literature and theoretical framework}

\section{Individual-level explanations of attitudes towards maternal employment}

Explanations of work-family attitudes at the individual level regularly centre on determinants related to self-interest or to the exposure to certain norms and ideas (Knudsen and Wærness 2001; Bolzendahl and Myers 2004; Davis and Greenstein 2009). The more individuals benefit from gender egalitarianism, the more egalitarian their attitudes should be. Female gender and higher social class are generally found to coincide with more positive attitudes towards maternal employment (Davis and Greenstein 2009). Being in the upper social strata makes it easier for mothers to return to work after child birth because their jobs are often characterised by more flexible working arrangements and better working conditions (McRae 1993). Most importantly, their higher income puts them in a better position to find and pay for childcare, making it easier for them to combine work and family life (ibid.). According to Schober and Scott (2012), being exposed to fewer constraints in combining work and family life contributes to a higher level of support for maternal employment by reducing psychological discomfort, often termed as cognitive dissonance. If there is a mismatch between a preferred work-family arrangement and attitudes towards maternal employment, this can cause cognitive dissonance. 
In such an instance, attitudes are expected to adjust to the situation of the household to correct for this mismatch.

Arguments related to the exposure to norms and ideas refer to factors such as the role of (parental) socialisation, education and personal experiences shaping attitudes towards maternal employment (Davis and Greenstein 2009). Education and being in a paid job expose individuals to gender egalitarian ideas and allow them to experience financial autonomy. In contrast, the experience of more traditional institutions or the confrontation with expectations of gender-stereotyped behaviour contribute to more conservative gender roles (ibid.). Examples might be religious practice, marriage or becoming a parent for the first time.

Several studies have tried to assess the extent of attitude change over time. One general finding is that attitudes are becoming more egalitarian (Crompton et al. 2005; Davis and Greenstein 2009), which can be attributed to both period and cohort effects. Nevertheless, there is also a notable persistence of more traditional gender role attitudes and a substantial variation across countries in the strength of attitude change, which is still poorly understood (Braun and Scott 2009). Cotter et al. (2011) find that the trend towards more gender egalitarian attitudes went into reversal in the mid-1990 s in the United States (US). They argue that this change is due to a new cultural frame, put forward by the media, which stresses the difficulties of combining work and family life and emphasises the importance of having a choice between intensive parenting and dual-earner arrangements. However, such a cultural explanation leaves open the possibility that the institutional design of family policies can make the ground either more or less fertile for arguments about the difficulties of work-family reconciliation.

\section{Policy feedback as a determinant of attitudes towards maternal employment}

Several contributions to the study of work-family attitudes adopt an institutionalist perspective to study the effects of family policies on attitudes towards maternal employment. In a crosssectional design across countries, Sjöberg (2004) and Kangas and Rostgaard (2007) show that attitudes towards maternal employment are constrained by institutions of family policies, such as parental leave and childcare services. The more established policies supporting dual-earner arrangements are, then the more widespread support for maternal employment tends to be. Employing a survey experimental design, Pedulla and Thébaud (2015) show that if policies supporting dual-earner arrangements compensate for the constraints in combining work and family life, attitudes shift towards being more favourable to a more gender egalitarian division of work and family life. A limitation of the crosssectional design of these studies is that it does not allow assessing the effects of expansive family policy reforms over time. In addition, these studies hardly pay attention to the possibility that, depending on the institutional characteristics of family policies, the benefits of expansive reforms might accrue to individuals from different social backgrounds in a highly unequal manner.

More recent studies employ single-country longitudinal research designs to examine how family policy reforms contribute to attitude change over time. These contributions report effects on gender egalitarian attitudes of parental leave reforms in Germany (Gangl and Ziefle 2015; Unterhofer and Wrohlich 2017) and of expansive 
childcare reforms in Norway (Ellingsæter and Gulbrandsen 2007; Ellingsæter et al. 2017) and Germany (Zoch and Schober 2018). Using panel data and taking into account regional variation in the expansion of childcare provision, Zoch and Schober (2018) show that the recent expansion of childcare provision for children under three has contributed to more egalitarian attitudes towards maternal employment in Germany. While the use of panel data is ideally suited to examine attitude change over time, the single-country design of these studies limits the possibility of analysing how inequality in access to childcare might condition the effects of expansion of childcare on attitudes across countries.

My theoretical framework draws on the institutionalist approaches to the study of attitudes towards maternal employment, and on theories of policy feedback more generally (cf. Sjöberg 2004; Gangl and Ziefle 2015; Zoch and Schober 2018). Theories of policy feedback argue that attitudes are socially constructed through existing policies (Pierson 1993; Mettler and Soss 2004; Campbell 2012; Kumlin and Stadelmann-Steffen 2014). Building on the prominent work by Pierson (1993), this literature claims that existing policies shape attitudes mainly through two mechanisms. First, individuals adjust their behaviour to existing policies according to cost-benefit calculations. From this perspective, differences in attitudes across countries reflect the pursuit of individual self-interest under different policy contexts. Individuals benefiting from a specific policy are likely to become dependent on the continued provision of this policy. As a consequence, they are also likely to become supporters of the policy and to defend it against cutbacks (e.g. Soss and Schram 2007; Busemeyer and Neimanns 2017). The second mechanism is about exposure to norms and ideas. The design of the policy status quo conditions the menu of alternatives that individuals consider as feasible, depending among other factors on how visible the consequences of a policy are for individuals (Soss and Schram 2007). A typical example is how policy design affects the (social) construction of different target groups. Many contributions distinguish between the consequences of universal and needs-based policy design, with the latter socially constructing distinct target groups that are often more vulnerable to stigmatisation (e.g. Schneider and Ingram 1993; Abou-Chadi and Finnigan 2019).

Building on such a perspective of policy feedback, an expansion of childcare provision should affect attitudes towards maternal employment by altering individual self-interest and through exposure to norms and ideas. With regard to the first mechanism, expansive childcare policies affect opportunity structures of individuals in their potential to combine work and family life. In order to affect attitudes, childcare policies need to make a difference in the possibility of parents obtaining childcare for their children and their prospects of pursuing paid work. Numerous studies have found that a higher availability, affordability and quality of childcare are associated with higher quality and quantity of maternal employment (e.g. Lewis et al. 2008; Hegewisch and Gornick 2011; Korpi et al. 2013). Achieving such outcomes requires substantial budgetary commitments by governments in terms of public spending (Van Lancker 2013). Generous public spending on childcare provision can reduce the constraints parents face in continuing to work while their children are young. The more publicly provided or subsidised childcare is available, the easier it should be for parents to actually use these services and the less they need to rely on often more expensive and sometimes less reliable informal forms of care provision. 
Attitudes can be expected to adjust to these new possibilities of work-care arrangements (Schober and Scott 2012) and should become more egalitarian along with expanding childcare provision.

As a second channel of influence, childcare policies shape the normative perceptions of what is seen as appropriate behaviour for men and women regarding the division of labour between paid employment and family life. Because the implications of childcare policies are visible beyond the core target group of parents with small children (Gangl and Ziefle 2015; Zoch and Schober 2018), I expect that an expansion of childcare provision affects normative evaluations of the issue of maternal employment throughout the population. If generous childcare policies reduce the opportunity costs of parents to combine work and family life, childcare provision is more likely to be perceived as helpful for child development and as a means of allowing women equal participation in the labour market (Sjöberg 2004), which should increase public acceptance of maternal employment. In contrast, if childcare provision is insufficient and parents struggle to cobble together care arrangements, sometimes informal or of low quality, childcare policies are more likely to be considered as an illegitimate interference in the family sphere (Morgan 2006; Cotter et al. 2011). In such a context, maternal employment is more likely to be portrayed as harmful for child and family life. The difficulties of reconciling work and family life are likely to be more salient and the notion of the importance of having "parental choice" between caregiving and paid employment is likely to enjoy greater popularity relative to the view that the equal rights of women in the labour market need to be ensured (ibid.). As a consequence, with limited availability of childcare provision, attitudes should remain more skeptical towards maternal employment.

Although childcare policies should be particularly relevant for parents of preschool children, the consequences of the institutional characteristics of provision should go beyond this relatively narrowly defined group. Individuals can have close family ties to parents with small children, remember their experiences when their children were still young, or they might become (grand)parents in the future. Unterhofer and Wrohlich (2017) provide an illustration of such social interaction effects showing that the recent German parental leave reform affected attitudes towards maternal employment in the grandparent generation. Individuals are also informed by their social networks, which are often socially stratified. Thus, while the effect of childcare provision on attitudes across socio-economic backgrounds should be the strongest for mothers with children below school age as the group most directly affected, socio-economic background should matter for attitude formation beyond parents with small children.

\section{The conditioning impact of inequality in childcare provision on attitudes towards maternal employment}

An expansion of childcare provision does not automatically improve accessibility of childcare. In fact, the relationship between expanding public childcare spending and increasing availability and accessibility of childcare is far from straightforward. In a panel study of European countries, Van Lancker (2018) does not find a direct effect of public spending increases on lowering social inequality in childcare enrolment, as measured by the extent to which families from higher income groups are 
overrepresented among the users of childcare. The effect of public spending on reducing inequality is only indirect, mediated via higher overall levels of enrolment. Despite increasing levels of public childcare spending, income inequality in enrolment can be highly persistent (Van Lancker 2013, 2018; Abrassart and Bonoli 2015; Van Lancker and Ghysels 2016).

The persistence of inequality in childcare enrolment has been found to hinge on the dimensions of universalism, and the state-market mix in childcare provision (Van Lancker and Ghysels 2016). With regard to the first dimension, in the presence of an often insufficient supply of childcare, having established access to childcare as a legal right bolsters parents' position in their attempt to use these services and implies an incentive for the government to expand provision. In addition, levels of private fees need to be sufficiently low to ensure that services are affordable for parents (Abrassart and Bonoli 2015). The second dimension concerns the difference between state- and market-based provisions. A strong reliance on private providers can complicate access to childcare because public authorities face more difficulties in ensuring equal access under such conditions (Hogrebe 2016). Private providers tend to be more expensive for parents, tend to concentrate provision in more affluent areas and are sometimes fraught by problems of low quality (Penn 2013), all of which contribute to lower take up of childcare.

In line with this institutional perspective on barriers to access to childcare, Pavolini and Van Lancker (2018) find social inequality in childcare enrolment to be driven primarily by insufficient availability or affordability, rather than by parental employment or cultural norms. Thus, as long as expansive childcare reforms do not address the underlying drivers of inequality in access to childcare, inequality is likely to persist. If barriers to access continue to be high and regulation of providers continues to be loose, increases in public childcare spending might increase quality of provision, provider profits (Penn 2013) or enrolment primarily among the more affluent families, which might even exacerbate inequality in enrolment. I further explore the relationship between expansive childcare spending, levels of enrolment and inequality in enrolment in the empirical analysis below.

Given the nontrivial relationship between expansion and accessibility of childcare, I consider inequality as a distinct characteristic of childcare provision. I expect social inequality in access to childcare to condition the effect of an expansion of childcare provision on attitudes towards maternal employment. A considerable share of parents with young children is likely to experience serious difficulties in combining paid work and family life if childcare provision is highly unequal. They may be priced out of access to expensive childcare services, forced to look for informal care options or face financial pressure as high childcare fees consume a large proportion of their salaries. At the same time, and as part of the emerging paradigm of a social investment welfare state (Morel et al. 2012; Hemerijck 2013), the expectations for all adults, including single parents, to participate in paid work have increased in most Western welfare states over the past decades with benefit systems and activation policies having adjusted accordingly (Kowalewska 2017). Taken together, more unequal access to childcare provision means that many individuals hardly benefit from expanding provision, but at the same time face pressure to combine work and family life to make ends meet. As a consequence, on average, individuals are likely to maintain a more skeptical view towards maternal employment: 
H1: The more unequal access to childcare is, the less an expansion of public childcare spending contributes to gender egalitarian attitudes.

Depending on the degree of inequality in access to childcare, the benefits of public childcare spending distribute unevenly across income groups. If childcare enrolment is stratified by income, individuals from higher-income groups benefit disproportionally from public spending on childcare. First, individuals from lower socio-economic backgrounds are often disadvantaged in access to childcare. If childcare is scarce, parents with a high socio-economic background are often better equipped in terms of social capital to access childcare, particularly in the presence of "fuzzy" access criteria and regulation (Ball and Nikita 2014; Hogrebe 2016). Second, high levels of private fees tend to price out lower-income parents (unless fees are applied in a progressive way, shifting payments to the more affluent parents; Abrassart and Bonoli 2015). As a consequence, with higher levels of public spending but persisting social inequality in access to care, it should primarily be the more affluent individuals who develop more gender egalitarian attitudes towards working mothers:

H2: The more unequal access to childcare is, the less an expansion of public childcare spending contributes to gender egalitarian attitudes among individuals with lower incomes compared to individuals with higher incomes.

The effects of childcare spending on attitudes towards maternal employment should furthermore vary by the extent to which individuals are directly affected by childcare provision. While the norms-based mechanism of policy feedback should apply throughout the population, the self-interest-based effect of expanding childcare on attitudes towards maternal employment should be particularly pronounced for directly affected groups (cf. Zoch and Schober 2018). This includes, in particular, parents with children below school age whose individual opportunity structures to combine work and family life are directly affected by childcare expansion. Prospective parents should also react sensitively to changes in childcare provision as the accessibility of childcare provision might impact their family planning and career decisions. Because women are still more often the primary caregiver in the household, I expect the effect of an expansion of childcare to be more pronounced for women than for men. Taken together, this leads to:

H3a: The more unequal access to childcare is, the less an expansion of public childcare spending contributes to gender egalitarian attitudes among women of childbearing age compared to men of that age group.

H3b: The more unequal access to childcare is, the less an expansion of public childcare spending contributes to gender egalitarian attitudes among women of childbearing age compared to women above childbearing age.

\section{Empirical analysis}

\section{Data and methods}

I use data from two waves of the ISSP module on "Family and Changing Gender Roles" $(2002,2012)$ to capture attitudes towards maternal employment. The sample 
comprises 18 European countries that are surveyed in both waves and for which the relevant macrolevel data exists, leading to a total of 36 country-year observations including 34,425 individuals after listwise deletion of observations with missing values. ${ }^{1}$ The dependent variable is taken from a battery of items on attitudes towards family and gender roles:

Do you think that women should work outside the home full-time, part-time or not at all under the following circumstances? When there is a child under school age. 1: Work full-time; 2: Work part-time; 3: Stay at home.

This item is the most direct measure of support or opposition towards paid employment of mothers with children below school age and is used among others by Kangas and Rostgaard (2007). Other items included in the ISSP capture gender ideology in a much broader sense and would therefore be likely to measure the effect of expanding childcare provision only in a more indirect way. Around $34 \%$ of respondents state that women with children below school age should stay at home. The share of respondents supporting full-time employment of mothers with small children is relatively small $(16 \%)$. Because the number of responses in this category is low, and to ease the presentation of the results by using multilevel logistic regression models, I merge the full-time and part-time categories (coded as 1) and use staying at home as the reference category (coded as 0 ). The results stay the same if I estimate multilevel ordered logistic regression models with the original coding of the variable instead.

The central independent variable at the microlevel is household income, which I recoded as income quintiles. The household's position in the income distribution should be decisive for whether families are able to access childcare. For example, household income decides whether parents are able to afford paying private fees which are an important component of inequality in access to childcare. Household income is likely to be endogenous to some extent to the effects of childcare provision on parental employment. To be nevertheless able to interpret household income as an indicator of the socio-economic position of a respondent, I control for the working status of a respondent and his or her partner (not working, working part-time or working full-time), for the relative income between the respondent and his/her partner, and for the partner's educational background (see the supplementary material for the detailed operationalisation). Respondent's educational attainment could be considered as an alternative indicator for the individual socioeconomic position because it captures potential earnings that could be realised, and the opportunity costs of not participating in the labour market. However, educational attainment is more likely to reflect not only the material position of an individual, but also the influence of norms and values as a determinant of attitudes (Davis and Greenstein 2009). For this reason, childcare reforms might matter less in affecting the role of educational background as a determinant of attitudes towards maternal employment compared to the household's position in the income

${ }^{1}$ The countries are Germany (DE), Great Britain (GB), Austria (AT), Ireland (IE), Norway (NO), Sweden (SE), Czech Republic (CZ), Slovenia (SI), Poland (PL), Spain (ES), Slovakia (SK), France (FR), Denmark (DK), Finland (FI), Hungary (HU), Netherlands (NL), Belgium-Flanders (BE), Portugal (PT). 
distribution. ${ }^{2}$ In the multivariate analysis, I include educational attainment as a control variable. The results largely stay the same if income is replaced with educational attainment as the moderating variable (see Figures A.4 and A.5 in the supplementary material).

Hypotheses $3 \mathrm{a}$ and $3 \mathrm{~b}$ specify the consequences of childcare spending to vary by gender and age. I include gender and age as control variables and estimate separate models for the pooled sample and for women under 45 (and for the reference groups of men under 45 and women above 45 to be presented in the supplementary material). Around 45 years is taken as a cutoff point because individuals below 45 should be most likely either to become parents in the near future or to have children below school age. ${ }^{3}$

Further individual-level control variables include those which are standard in studies on the determinants of gender role attitudes (e.g. Bolzendahl and Myers 2004; Sjöberg 2004). I control for having children below and above school age living in the household, whether the respondent is living together with a partner, and religious practice. The detailed coding of these and the following variables is described in the supplementary material.

At the macrolevel, I use levels of public spending as a central indicator for expansionary childcare reforms. While public childcare spending is only an imprecise measure of to what extent families actually benefit from increases in public spending, it is nevertheless highly informative as an indicator of the government's commitment to devote (additional) public resources to the provision of childcare services. The measure of public spending captures cash and in-kind spending on childcare and preprimary education [as a percentage of gross domestic product (GDP); OECD 2017]. I include childcare spending as long-term averages (averaged between 2002 and 2012), and as short-term deviations from those averages in the years 2002 and 2012. While short-term spending changes are the more direct indicator of expansionary childcare reforms which should affect attitudes, also longterm average levels of spending can contribute to changing attitudes over time since they affect individuals' everyday experience with the country's childcare system. I explain the methodological rationale for distinguishing between average levels and changes in spending in more detail below.

To capture to what extent parents from different social backgrounds benefit from childcare provision, I use Van Lancker's (2018) relative index of inequality in childcare use as a factor conditioning the impact of public childcare spending. This index measures to what extent full-time equivalent childcare enrolment for children aged zero to two years depends on families' equivalised disposable income. A value of zero would imply equal enrolment across income groups; positive values mean that more affluent parents are overrepresented among the users of childcare. Data exists for the years 2006-2012. Again, I include the average value of inequality in enrolment over time and the deviation from that average in 2006 and 2012. Ideally, data for this indicator would be available for the year 2002. Thus, I have

\footnotetext{
${ }^{2}$ In addition, in this study, income should be a more direct determinant of attitudes compared to educational attainment, because also social inequality in childcare enrolment is measured on the base of income.

${ }^{3}$ As a robustness check, I run additional models including only parents and mothers below 45 (Figure A.2 in the supplementary material). These models lead to the same results.
} 
to assume that inequality in enrolment in 2006 sufficiently reflects inequality in 2002. Given that variation in inequality over time is considerably smaller than variation across countries, this assumption appears appropriate (see Table A.1). Obviously, social inequality in childcare enrolment can be the result of a range of factors related to the institutional characteristics of childcare policies and beyond (Van Lancker and Ghysels 2016). Unfortunately, using more direct policy measures underlying inequality in access to childcare is infeasible for an analysis across time and countries due to lack of appropriate data (Van Lancker 2018, 287). Nevertheless, Pavolini and Van Lancker (2018) demonstrate that inequality in childcare enrolment is primarily associated with perceived constraints in availability and affordability of childcare. This finding suggests that it is reasonable to use this indicator as a proxy for the unequal benefits of childcare provision inherent in the respective institutional characteristics of childcare policies. Table A.1 in the supplementary material shows summary statistics of the dependent and central independent variables.

To assess the validity of the results, I estimate additional model specifications. To examine to what extent expanding childcare provision actually affects employment prospects of women, I run models with being in paid work as a dependent variable. In additional models, I add levels of female labour force participation and unemployment rates as control variables to make sure that the effects I observe are not due to a general trend of rising female employment shares or depend on the labour market context. I discuss the operationalisation of these variables and the results of these models in the supplementary material and at the end of the empirical section.

I run multilevel logistic regression models, following the propositions by Fairbrother (2014) for analysing repeated crosssectional survey data. This specification allows modelling change over time in the dependent variable as a function of change over time in the independent variable and/or of a time-invariant independent variable (ibid., 119). I estimate random intercept models and include countries and country-years as random effects to account for the nested data structure with individuals nested in country-years nested in countries. ${ }^{4}$ Year is included as fixed effect with a dummy indicating the respective year of ISSP data to control for common time trends that are unrelated to changes in childcare spending. Public spending on childcare services is the central independent level at the macrolevel that is variant over time. Because the effects of long-term average spending levels might differ from changes over time in this variable, I calculate country-specific means of public childcare spending and period-specific deviations from those means to disentangle crosssectional and over-time effects on work-family attitudes. ${ }^{5}$ Short-term changes in childcare spending should have the most direct effect on changing attitudes over time. Nevertheless, the effects of long-term average spending levels can also be expected to contribute to attitude change over time. More generous childcare provision should be associated with lower constraints in combining work and family life and should thereby contribute over time to more egalitarian attitudes towards

\footnotetext{
${ }^{4}$ The results hold if income is included additionally as lower-level random effects (Heisig and Schaeffer 2019).

${ }^{5}$ Because long-term averages and short-term deviations of spending might not be independent of each other, it is necessary to include both terms in the analysis to avoid biased estimates.
} 
maternal employment, irrespective of short-term changes in spending. To take this effect into account, I specify a "growth curve effect" (ibid., 125) by including an interaction between the average spending level and the time dummy in a separate step of the analysis. A positive coefficient of the interaction term would represent a long-term effect of expansionary childcare reforms because higher average levels of public childcare spending would shift attitudes over time into a more egalitarian direction.

Analysing the effects of changes in spending over time with repeated crosssectional surveys allows for a more robust interpretation in terms of causal effects compared to previous crosscountry comparative studies that relied on a crosssectional analysis of childcare policies (Sjöberg 2004; Kangas and Rostgaard 2007). Though ideally crossnational panel data would be used, analysing the effects of spending changes on attitudes with repeated crosssectional surveys can provide additional insights since changes in spending and attitudes are less likely than values that are observed at only one point in time to reflect some unobserved country characteristics.

I begin the presentation of the results by showing the associations between levels and changes in public childcare spending, enrolment rates and inequality in enrolment in Figure 1. Table 1 reports the results from the subsequent multilevel logistic regressions. The main aim of the analysis is to assess the effect of an expansion of childcare spending for different socio-economic groups over time, conditioned by inequality in access to childcare. Therefore, in the next step of the analysis, I interact changes in public childcare spending with inequality in enrolment and respondent's household income. I run the models separately for the pooled sample and for women under 45 . In an additional step, I examine how inequality conditions the effects of different spending levels unfolding over time (i.e. Fairbrother's (2014) "growth curve effect"), specifying an interaction between levels of public childcare spending, inequality in enrolment, respondent's household income, and the time dummy. To be able to interpret the interaction effects in a meaningful way, I follow the advice given by Brambor et al. (2006) and discuss the results of the interaction effects based on average marginal effect plots (Figures 2 and 3). The full regression results are reported in the supplementary material.

\section{Results}

Figure 1 shows the distribution of the 18 European countries included in this study with regard to levels of public spending (upper panels), childcare enrolment (lower panels) and inequality in childcare enrolment, averaged over time (left panels) and as change between both observation periods (right panels). The main message the upper panels in Figure 1 convey is that there is no clear relationship between public spending on childcare and inequality in enrolment, echoing earlier findings by Van Lancker and Ghysels (2016) and Van Lancker (2018). It is true that Denmark and Sweden combine the highest levels of public spending on childcare provision, almost $1.5 \%$ of GDP, with close to equal enrolment across income groups, whereas public spending levels are among the lowest in Poland and Ireland, the two countries with by far the highest social inequality in childcare enrolment. However, 

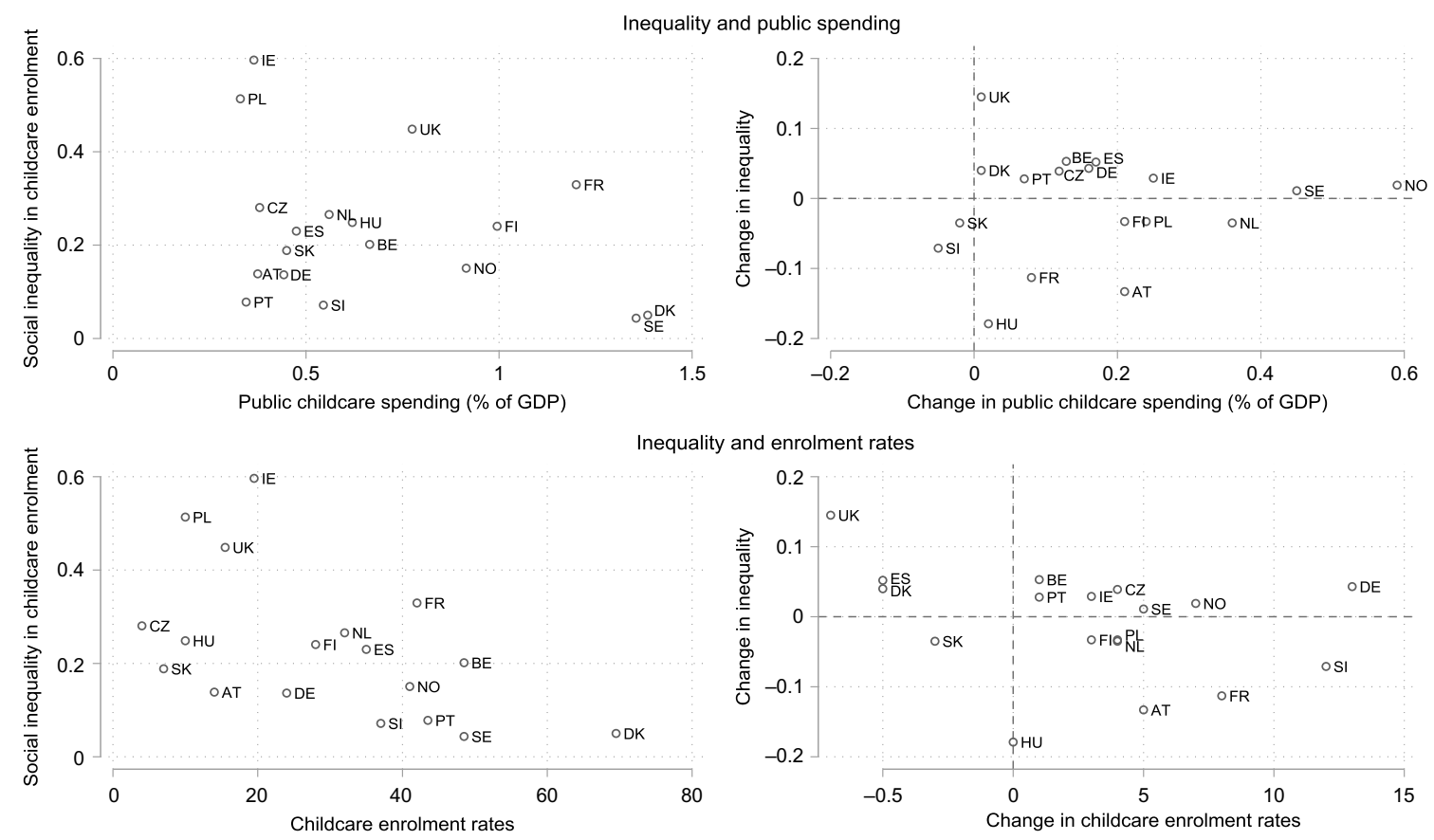

Figure 1. Average levels and changes in public childcare spending, childcare enrolment rates, and income inequality in childcare enrolment.

Note: For country labels see footnote 1 .

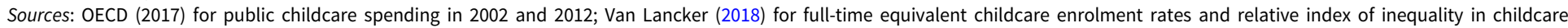
enrolment in 2006 and 2012. 
Table 1. Multilevel random intercept regressions: attitudes towards maternal employment; maximum likelihood estimates

\begin{tabular}{|c|c|c|c|c|}
\hline & M1 & M2 & M3 & M4 \\
\hline VARIABLES & $\begin{array}{r}\text { Attitudes towards } m \\
\text { employment }\end{array}$ & & & \\
\hline Household income: Q1 & $-0.182^{\star \star \star}$ & $-0.183^{\star \star \star}$ & $-0.183^{\star * \star}$ & $-0.182^{\star \star \star}$ \\
\hline (ref: Q3) & $(0.041)$ & $(0.041)$ & $(0.041)$ & $(0.041)$ \\
\hline \multirow[t]{2}{*}{ Q2 } & -0.059 & -0.059 & -0.059 & -0.058 \\
\hline & $(0.039)$ & $(0.039)$ & $(0.039)$ & $(0.039)$ \\
\hline \multirow[t]{2}{*}{ Q4 } & $0.133^{\star \star *}$ & $0.134^{\star \star *}$ & $0.133^{\star \star \star *}$ & $0.133^{\star \star \star}$ \\
\hline & $(0.040)$ & $(0.040)$ & $(0.040)$ & $(0.040)$ \\
\hline \multirow[t]{2}{*}{ Q5 } & $0.200^{\star \star *}$ & $0.201^{\star \star \star}$ & $0.201^{\star * *}$ & $0.201^{\star * *}$ \\
\hline & $(0.043)$ & $(0.043)$ & $(0.043)$ & $(0.043)$ \\
\hline Below upper secondary education & $-0.638^{\star \star \star}$ & $-0.637^{\star \star *}$ & $-0.639^{\star \star \star}$ & $-0.641^{\star \star \star}$ \\
\hline (ref: Tertiary education) & $(0.043)$ & $(0.043)$ & $(0.043)$ & $(0.043)$ \\
\hline \multirow[t]{2}{*}{ Upper secondary education } & $-0.393^{* \star *}$ & $-0.392^{\star \star \star}$ & $-0.392^{\star \star *}$ & $-0.392^{\star \star \star}$ \\
\hline & $(0.041)$ & $(0.041)$ & $(0.041)$ & $(0.041)$ \\
\hline Paid work (part-time) & $0.133^{\star \star \star}$ & $0.133^{\star \star \star}$ & $0.134^{\star \star \star}$ & $0.135^{\star \star \star}$ \\
\hline (ref: not in paid work) & $(0.049)$ & $(0.049)$ & $(0.049)$ & $(0.049)$ \\
\hline \multirow[t]{2}{*}{ Paid work (full-time) } & $0.196^{\star \star *}$ & $0.195^{\star \star \star}$ & $0.195^{\star \star *}$ & $0.195^{\star * \star}$ \\
\hline & $(0.033)$ & $(0.033)$ & $(0.033)$ & $(0.033)$ \\
\hline Partner not in paid work & -0.060 & -0.060 & -0.059 & -0.060 \\
\hline (ref: no partner) & $(0.063)$ & $(0.063)$ & $(0.063)$ & $(0.063)$ \\
\hline \multirow[t]{2}{*}{ Partner in part-time work } & -0.038 & -0.037 & -0.035 & -0.036 \\
\hline & $(0.077)$ & $(0.077)$ & $(0.076)$ & $(0.076)$ \\
\hline \multirow[t]{2}{*}{ Partner in full-time work } & 0.052 & 0.052 & 0.053 & 0.052 \\
\hline & $(0.059)$ & $(0.059)$ & $(0.059)$ & $(0.059)$ \\
\hline $\begin{array}{l}\text { Partner: Below upper secondary } \\
\text { education }\end{array}$ & $-0.141^{\star \star \star}$ & $-0.140^{\star \star \star}$ & $-0.145^{\star \star \star}$ & $-0.143^{\star \star \star}$ \\
\hline (ref: no partner) & $(0.052)$ & $(0.052)$ & $(0.051)$ & $(0.051)$ \\
\hline \multirow[t]{2}{*}{$\begin{array}{l}\text { Partner: Upper secondary } \\
\text { education }\end{array}$} & -0.061 & -0.061 & -0.066 & -0.064 \\
\hline & $(0.055)$ & $(0.055)$ & $(0.055)$ & $(0.055)$ \\
\hline \multirow[t]{2}{*}{ Partner: Tertiary education } & $0.147^{\star \star}$ & $0.146^{\star \star}$ & $0.142^{\star \star}$ & $0.139^{\star *}$ \\
\hline & $(0.068)$ & $(0.068)$ & $(0.068)$ & $(0.067)$ \\
\hline Relative income: no own income & $-0.620^{\star \star *}$ & $-0.620^{\star \star \star}$ & $-0.618^{\star \star \star}$ & $-0.616^{\star \star \star}$ \\
\hline (ref: no partner) & $(0.089)$ & $(0.089)$ & $(0.089)$ & $(0.089)$ \\
\hline \multirow[t]{2}{*}{$\begin{array}{l}\text { Relative income: partner earns } \\
\text { more }\end{array}$} & 0.073 & 0.072 & 0.074 & 0.075 \\
\hline & $(0.066)$ & $(0.066)$ & $(0.066)$ & $(0.066)$ \\
\hline
\end{tabular}


Table 1. (Continued)

\begin{tabular}{|c|c|c|c|c|}
\hline & M1 & M2 & M3 & M4 \\
\hline \multirow[t]{2}{*}{$\begin{array}{l}\text { Relative income: both earn the } \\
\text { same }\end{array}$} & $0.206^{\star \star \star}$ & $0.205^{\star \star \star}$ & $0.207^{\star \star \star}$ & $0.208^{\star \star \star}$ \\
\hline & $(0.071)$ & $(0.071)$ & $(0.071)$ & $(0.071)$ \\
\hline \multirow[t]{2}{*}{$\begin{array}{l}\text { Relative income: partner earns } \\
\text { less }\end{array}$} & 0.098 & 0.097 & 0.098 & 0.099 \\
\hline & $(0.067)$ & $(0.067)$ & $(0.066)$ & $(0.066)$ \\
\hline \multirow[t]{2}{*}{$\begin{array}{l}\text { Relative income: only respondent } \\
\text { has income }\end{array}$} & $-0.458^{\star \star \star}$ & $-0.458^{\star \star \star}$ & $-0.456^{\star \star \star}$ & $-0.454^{\star \star \star}$ \\
\hline & $(0.085)$ & $(0.085)$ & $(0.085)$ & $(0.084)$ \\
\hline \multirow[t]{2}{*}{ Age } & $-0.013^{\star \star \star}$ & $-0.013^{\star \star \star}$ & $-0.013^{\star \star \star}$ & $-0.013^{\star \star \star}$ \\
\hline & $(0.001)$ & $(0.001)$ & $(0.001)$ & $(0.001)$ \\
\hline \multirow[t]{2}{*}{ Female } & $0.450^{\star \star \star}$ & $0.449^{\star \star \star}$ & $0.449^{\star \star \star}$ & $0.449^{\star \star \star}$ \\
\hline & $(0.030)$ & $(0.030)$ & $(0.030)$ & $(0.030)$ \\
\hline \multirow[t]{2}{*}{ Children in school age } & $-0.110^{\star \star \star}$ & $-0.110^{\star \star \star}$ & $-0.110^{\star \star \star}$ & $-0.110^{\star \star \star}$ \\
\hline & $(0.031)$ & $(0.031)$ & $(0.031)$ & $(0.031)$ \\
\hline \multirow[t]{2}{*}{ Toddlers } & -0.046 & -0.046 & -0.045 & -0.046 \\
\hline & $(0.040)$ & $(0.040)$ & $(0.040)$ & $(0.040)$ \\
\hline \multirow[t]{2}{*}{ Religious practice } & $-0.255^{\star \star \star}$ & $-0.254^{\star \star \star}$ & $-0.253^{\star \star *}$ & $-0.254^{\star \star \star}$ \\
\hline & $(0.028)$ & $(0.028)$ & $(0.028)$ & $(0.028)$ \\
\hline Year $=2012$ & $0.540^{\star \star \star}$ & $0.599^{\star \star \star}$ & $0.628^{\star \star \star}$ & $0.671^{\star \star \star}$ \\
\hline (Ref: year $=2002)$ & $(0.120)$ & $(0.171)$ & $(0.167)$ & $(0.120)$ \\
\hline \multirow[t]{2}{*}{ Public childcare spending (mean) } & & $0.094^{\star \star \star}$ & $0.065^{\star \star}$ & 0.031 \\
\hline & & $(0.032)$ & $(0.027)$ & $(0.029)$ \\
\hline \multirow[t]{2}{*}{ Public childcare spending (diff) } & & -0.035 & -0.042 & -0.064 \\
\hline & & $(0.073)$ & $(0.071)$ & $(0.051)$ \\
\hline \multirow[t]{2}{*}{ Childcare inequality (mean) } & & & $-0.202^{\star \star \star}$ & $-0.139 * \star$ \\
\hline & & & $(0.059)$ & $(0.066)$ \\
\hline \multirow[t]{2}{*}{ Childcare inequality (diff) } & & & 0.173 & $0.198^{*}$ \\
\hline & & & $(0.152)$ & $(0.109)$ \\
\hline \multirow[t]{2}{*}{$\begin{array}{l}\text { Public childcare spending (mean)* } \\
\text { year }=2012\end{array}$} & & & & $0.069^{\star \star \star}$ \\
\hline & & & & $(0.026)$ \\
\hline \multirow[t]{2}{*}{$\begin{array}{l}\text { Childcare inequality (mean) }{ }^{\star} \\
\text { year }=2012\end{array}$} & & & & $-0.127^{\star \star}$ \\
\hline & & & & $(0.057)$ \\
\hline \multirow[t]{2}{*}{ Constant } & $1.410^{\star \star \star}$ & $1.381^{\star \star \star}$ & $1.367^{\star \star \star}$ & $1.345^{\star \star \star}$ \\
\hline & $(0.163)$ & $(0.156)$ & $(0.139)$ & $(0.127)$ \\
\hline Observations & 34,425 & 34,425 & 34,425 & 34,425 \\
\hline Number of countries & 18 & 18 & 18 & 18 \\
\hline Number of country-years & 36 & 36 & 36 & 36 \\
\hline
\end{tabular}


Table 1. (Continued)

\begin{tabular}{|c|c|c|c|c|}
\hline & M1 & M2 & M3 & M4 \\
\hline \multirow{2}{*}{$\begin{array}{l}\text { Random intercept variance } \\
\text { (country) }\end{array}$} & $0.252^{\star \star}$ & $0.152^{\star \star}$ & 0.072 & $0.101^{\star \star}$ \\
\hline & $(0.108)$ & $(0.075)$ & $(0.048)$ & $(0.045)$ \\
\hline \multirow{2}{*}{$\begin{array}{l}\text { Random intercept variance } \\
\text { (country-year) }\end{array}$} & $0.122^{\star \star \star}$ & $0.121^{\star \star \star}$ & $0.113^{\star \star \star}$ & $0.054^{\star \star \star}$ \\
\hline & $(0.043)$ & $(0.043)$ & $(0.040)$ & $(0.020)$ \\
\hline
\end{tabular}

Note: Standard errors in parentheses.

${ }^{\star \star *} p<0.01,{ }^{\star \star} p<0.05,{ }^{\star} p<0.1$

besides these four countries, there is substantial variation across countries in terms of spending levels and inequality that does not exhibit any clear association between the two variables (the bivariate correlation is $r=-0.32 ; p=0.20$ ). The same holds true when examining changes in inequality and spending over time $(r=0.09$; $\mathrm{p}=0.73$ ). Governments in nearly all countries increased public spending on childcare between 2002 and 2012, which could be interpreted as an attempt to meet the Barcelona targets of increasing enrolment levels. Enrolment rates did indeed increase in most countries (lower-right panel in Figure 1). Yet, increases in public spending and enrolment did not prevent inequality in enrolment from even rising in some countries. Belgium is an illustrative and well-documented case with a rate of childcare enrolment similar to Sweden, but with inequality in enrolment exceeding substantially, and increasingly so, the relatively egalitarian Swedish enrolment pattern (lower panels in Figure 1; Van Lancker and Ghysels 2012). Also in Germany, inequality in enrolment has been rising over the observation period, although Germany experienced the largest expansion of enrolment of the whole sample.

Taken together, the results in Figure 1 demonstrate that an expansion of childcare spending does not necessarily reduce inequality in access to childcare and that spending and inequality should instead be considered as separate dimensions. To what extent additional public childcare spending benefits families across income backgrounds depends on the broader institutional context of childcare provision. The following multivariate analysis sheds further light on how inequality in access to childcare conditions the effects of expanding childcare spending on attitudes towards maternal employment across income groups.

Table 1 reports the estimated coefficients from the multilevel logistic regression models. Model 1 includes only individual-level variables, Models 2-4 subsequently add the variables of public childcare spending and childcare inequality. Model 4 adds a growth curve specification (cf. Fairbrother 2014), which allows evaluating how the effect of levels of spending and inequality unfold over time. ${ }^{6}$ The interaction of household income with the macrolevel variables, as well as separate models for the subsample of women of childbearing age, is included in a subsequent step of the analysis.

\footnotetext{
${ }^{6}$ For ease of interpretation, I mean-center the macrolevel variables and multiply them by 10 . This implies that a one unit change in spending and inequality represents a change in 0.1 percentage points of gross domestic product (GDP) of spending [1.19 standard deviations (SDs)] and 0.1 point change in the index of income inequality in childcare enrolment (0.39 SDs), respectively.
} 

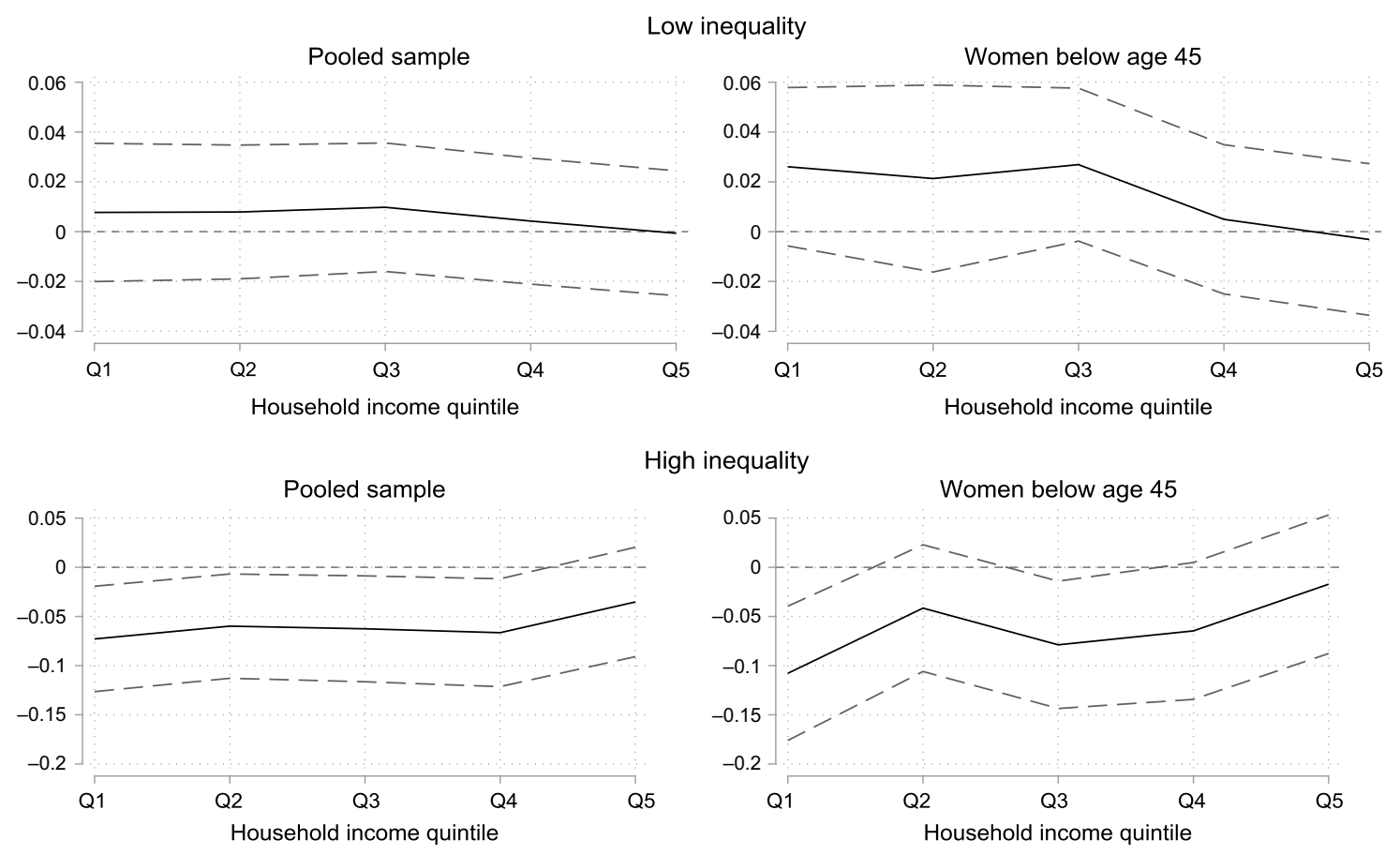

High inequality

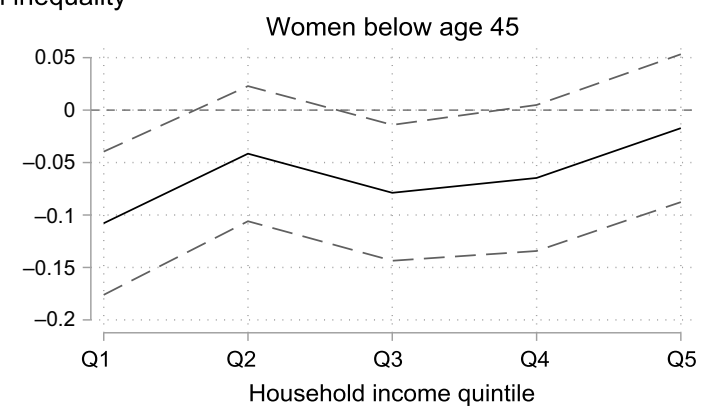

Figure 2. Average marginal effects of changes in public childcare spending on attitudes towards maternal employment conditioned by inequality in childcare enrolment.

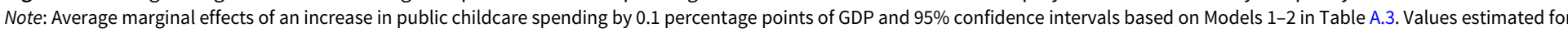
low- and high-inequality countries at the 10th and 90th percentile of levels of inequality in childcare enrolment. 

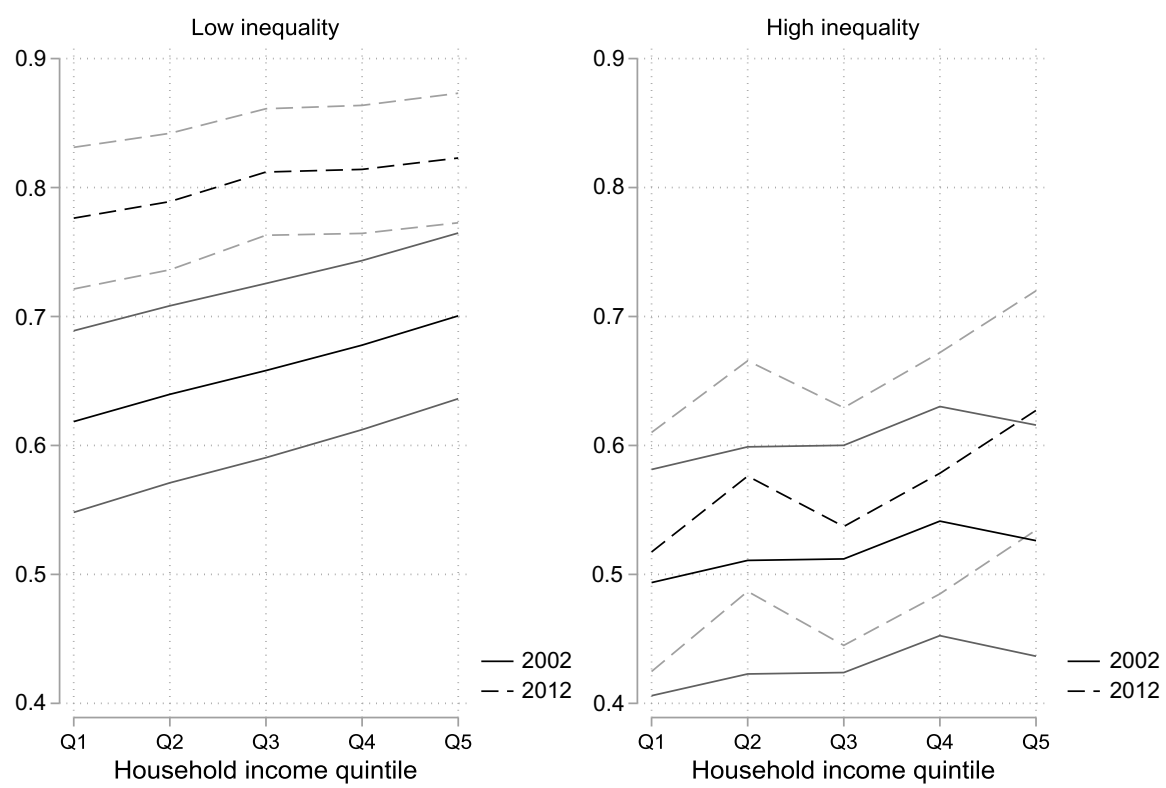

Figure 3. Predicted probabilities of support for maternal employment in 2002 and 2012 in low- and high-inequality countries.

Note: Predicted probabilities and 95\% confidence intervals based on Model 1 in Table A.4. Values estimated for 2002 and 2012 and for low- and high-inequality countries at the 10 and 90 percentile of levels of inequality in childcare enrolment.

The coefficient estimates of the individual-level determinants confirm earlier findings of the role of self-interest and norms as determinants of attitudes towards maternal employment. Higher household income as an indicator of the socioeconomic situation of a respondent is associated with significantly more gender egalitarian work-family attitudes. As argued above, this effect represents lower opportunity costs for parents in a high socio-economic position to combine work and family life. The effect of income is substantial in size. Moving from the lowest to the highest income quintile increases the likelihood of being supportive of maternal employment by 7.29 percentage points. ${ }^{7}$ In line with this finding, a higher level of respondent's and partner's formal education, being in paid work, and a more equal contribution of both partners to household income, are also associated with a higher likelihood of more egalitarian attitudes (cf. Schober and Scott 2012). In contrast, having children reduces support for maternal employment, which is argued to be related to experience and imposed expectations of traditional gender roles in parenting (Davis and Greenstein 2009). However, this effect is significant only for children of school age. Women are more supportive of maternal employment, which reflects the view that promoting maternal employment could help to improve

\footnotetext{
${ }^{7}$ The results underlying this and the following presentations of marginal effect estimates, and the results of t-tests which were used to evaluate the statistical significance of differences in marginal effect estimates are available upon request.
} 
women's position in the labour market (ibid.). Finally, age and religious practice are associated with more traditional attitudes towards maternal employment, which should reflect exposure to more traditional gender norms. In addition, there is a time trend leading attitudes to become more egalitarian between the two waves of observation in 2002 and 2012.

In Models 2-4, I add the macrolevel variables of public childcare spending and inequality in childcare provision to examine how the accessibility of childcare as a policy supporting dual-earner arrangements affects attitudes towards maternal employment. Model 2 shows that in countries with higher levels of public childcare spending, the public is more supportive of maternal employment. This result echoes the findings by Sjöberg (2004) and Kangas and Rostgaard (2007) that family policies supporting dual-earner arrangements are associated with more egalitarian workfamily attitudes. However, it is notable that the coefficient of changes in childcare spending over time is insignificant and even negatively signed. Thus, an expansion of childcare spending does not lead per se to more egalitarian attitudes. Indeed, as Model 3 shows, while holding childcare spending constant, more unequal childcare enrolment is associated with significantly more skepticism towards maternal employment. Again, this effect is significant only for the long-term average level of inequality. While a shift in the level of public spending by one standard deviation (SD) is associated with a change in the predicted probability of supporting maternal employment by 4.26 percentage points, a shift in the level of inequality by one SD is associated with an increase in the likelihood of holding more traditional attitudes by 5.91 percentage points. Thus, if childcare enrolment is socially unequal, this counteracts the gender egalitarian effect of higher levels of public spending. This finding highlights the relevance of taking inequality in access to childcare into account, which has been neglected by previous research.

Finally, Model 4 indicates that differences in spending and inequality might over time perpetuate the differences across countries in attitudes towards maternal employment, as indicated by the statistically significant interaction terms between year and spending, and inequality, respectively. While a higher level of spending amplifies the time trend towards more egalitarian attitudes, a higher level of inequality reduces this trend. I explore the implications of this finding in further detail below.

In the next step, I examine how inequality in childcare enrolment conditions the effect of an expansion of childcare on attitudes towards maternal employment (Hypothesis 1), and how this effect unfolds across income groups (Hypothesis 2) and affected versus nonaffected groups (Hypotheses $3 \mathrm{a}$ and $3 \mathrm{~b}$ ). I calculate average marginal effects of changes in public spending across the different samples by income groups for a low- and high-inequality scenario (at the 10th and 90th percentile of inequality in childcare enrolment) and present a graphical illustration of the results in Figure 2. The full regression results are reported in Table A.3 in the supplementary material.

The marginal effect estimates for the pooled sample (left plots in Figure 2) demonstrate that the effect of an expansion of childcare is conditioned by inequality in childcare enrolment (Hypothesis 1). If inequality in access to childcare is low, the marginal effect estimates of spending changes are positively signed, but not significantly related to attitudes towards maternal employment across income groups. 
Spending changes appear to benefit the lower-income groups in particular. The point estimates are the largest for the three lowest-income quintiles. Differences across income groups are insignificant, however. In contrast, if access to childcare is highly unequal, public spending increases are associated with a shift towards less egalitarian attitudes. The effects are the strongest and significant for individuals in the four lowest-income quintiles. For individuals in the lowest-income quintile, an increase in public spending by 0.1 percentage points of GDP (1.17 SD) is associated with a decrease in the likelihood of gender egalitarian work-family attitudes by 7.29 percentage points. This finding lends support to the expectations spelled out above that if access to childcare is highly unequal, combining work and family life should be most difficult for lower-income families, which should be reflected in more skepticism towards maternal employment (Hypothesis 2).

The insignificance of spending increases on attitudes in the low-inequality countries suggests that the transformative power of expanding childcare should not be overestimated. A longer time period than the 10 years between the first and second observation period underlying the models presented here might be needed for attitude change to cumulate. In contrast, the finding of significant negative effects in the high-inequality countries is to some extent surprising. One explanation could be that expansive childcare policies might come in conjunction with expectations and requirements for mothers to combine work and family life, which are particularly difficult to fulfil if access to childcare is limited (Cotter et al. 2011; Kowalewska 2017). Note, however, that the marginal effect estimates of spending changes allow only limited conclusions regarding overall attitude trends over time because they disregard the effects of long-term average spending levels unfolding over time. I pick up on this point below.

How do the effects change for groups that are more directly affected by the expansion of childcare provision? According to Hypotheses 3a and 3b, women of childbearing age should be most affected by childcare provision. For those women, the conditioning impact of inequality in access to childcare should be most pronounced. This is confirmed by the results in Figure 2 (right plots). If inequality in access to childcare is low, the effects of spending changes are still insignificant, but the point estimates are stronger, more than double in size for the three lowestincome groups. If inequality is high, childcare expansion is associated with a shift towards less egalitarian attitudes, including among women in the lowest-income quintile, and the point estimate increases in size compared to the pooled sample. Thus, whereas an increase in public spending by 0.1 percentage points of GDP leads to a higher likelihood of more egalitarian attitudes by 2.61 percentage points among low-income women in countries with low inequality in childcare provision, it reduces the likelihood by 10.78 percentage points in countries with high inequality. The marginal effect estimates for the reference groups of men under 45 and women above 45 are located largely in between the estimates of the pooled sample and the sample of women under 45 (Figure A. 1 in the supplementary material). This finding confirms the expectation that women are more affected than men by an expansion of childcare provision, given that they are still more often the primary caregiver (cf. Zoch and Schober 2018).

Taken together, the results in Figure 2 provide support for Hypotheses 1-3. Where access to childcare is more unequal, lower-income families benefit less from 
an expansion of childcare provision. Attitudes among lower-income individuals become even more traditional in response to an expansion of childcare in such circumstances (Hypothesis 1 and 2). This effect is most pronounced for women of childbearing age who are most directly materially affected by an expansion of childcare (Hypotheses 3a and 3b). The results of the marginal effects of spending changes in Figure 2 suggest that over time attitudes towards maternal employment might become more homogenous between low- and high-income earners in countries with egalitarian access to childcare provision, whereas divergence might increase in countries with unequal access. In addition, the stronger positive effect of childcare expansion in low-inequality countries implies that differences across countries in terms of support for maternal employment might intensify.

To fully assess the role of childcare spending and inequality for trends in attitudes over time, I calculate predicted probabilities of support for maternal employment building on the growth curve specification in Model 4 in Table 1. I reestimate this model, adding additional interaction terms between year, level of childcare inequality, level of childcare spending and income. This model specification takes into account that attitude change can also be the result of the effects of long-term average spending levels unfolding over time. Figure 3 reports predicted probabilities of support for maternal employment in low- and high-inequality countries in 2002 and 2012. ${ }^{8}$ The full regression results are reported in Table A.4 in the supplementary material.

Figure 3 demonstrates that inequality in access to childcare conditions not only the effect of spending changes on attitudes, but also overall trends in attitudes towards maternal employment over time. Averaged across income quintiles, attitudes have become more egalitarian between 2002 and 2012 in both sets of countries, but this change has been more pronounced and is only statistically significant in countries with more equal access to childcare. Whereas the likelihood of having egalitarian attitudes increased from 65.89 to 80.29 in countries with low inequality, the change was only 5.05 in high-inequality countries. The fact that attitude change was stronger in the low-inequality countries, despite attitudes having already been more egalitarian in those countries in 2002, implies that the difference in attitude trends across countries is not due to saturation effects (if anything, a saturation effect might exist for individuals in the highest income quintile in countries with low inequality). In addition, inequality in access to childcare strongly conditions the composition of this trend across income groups. In countries with equal access to childcare, attitude change was most pronounced in the lowest-income quintile (15.77 percentage points difference). In the unequal countries, individuals in the highest income quintile experienced the strongest change in attitudes (10.10 percentage points difference), whereas attitudes of individuals in the lowest-income quintile barely changed. Taken together, where childcare provision is expanded but provision remains unequal, families in a lower socio-economic position hardly benefit from improved possibilities to combine work and family life. If this situation persists, attitudes towards maternal employment will become increasingly polarised

\footnotetext{
${ }^{8}$ The predicted probabilities are estimated for the respective average values of levels of public childcare spending in countries with below and above average values of inequality in childcare enrolment in the respective year.
} 
between lower-income individuals, who remain more skeptical of maternal employment, and high-income individuals, who benefit disproportionally from expanded, but unequal childcare provision.

\section{Robustness issues}

The use of alternative model specifications lends further support to the findings. For reasons of space, the operationalisation of these variables and the results of these additional models are presented in greater detail in the supplementary material (Table A.2 and Figure A.3). According to the line of argument, the conditioning effect of inequality in access to childcare on attitudes should be mediated by the effect of childcare provision on patterns of female employment (though, by focusing on employment, it is not possible to measure the actual burden of combining work and family life under the respective institutional context). Figure A.3 confirms this reasoning. Replacing the attitudinal dependent variable with an indicator of whether individuals are in paid employment or not for a sample of women below the age of 45 reveals significant positive effects of increasing childcare spending for women in the two lowest-income quintiles in low-inequality countries, but not in highinequality countries. This is further evidence that in particular lower-income families benefit from expanding childcare provision, but only if access to childcare is sufficiently egalitarian. To rule out that a general trend of rising female employment shares or the context of the labour market drive the results, I add female labour force participation rates and unemployment rates as macrolevel variables to the models in Table 1. The results in Table A.2 show that higher shares of female employment are associated with more egalitarian attitudes towards maternal employment (Model 1). However, if levels of public childcare spending and inequality in childcare enrolment are included (Model 3), female employment rates become insignificant while childcare spending and inequality remain significant. Controlling for unemployment rates also does not alter the effects of the childcare variables (Table A.2, Models 4-6). Taken together, these findings corroborate the claim that inequality in access to childcare provision crucially matters for how expansive public childcare spending benefits individuals across socio-economic backgrounds, with distinct effects on individuals' attitudes towards maternal employment.

\section{Conclusions}

While scholars referring to the emerging paradigm of a social investment welfare state sometimes normatively call for - and sometimes empirically find - expansive reforms of childcare services to take place, persistent variation in the institutional characteristics of childcare provision across countries remains. In most Western countries, access to childcare is socially unequal due to insufficient availability or affordability of services. We still face difficulties in explaining variation in childcare policies across countries as well as in identifying the political support structure responsible for reform patterns. Changes in public attitudes towards maternal employment have been suggested as a possible explanation for this variation (Morgan 2013; Hemerijck 2015; Blome 2017; Schwander 2018). Scholars examining the determinants of attitudes towards maternal employment find attitudes to 
become more egalitarian over time, but again substantial crosscountry variation exists, which is still poorly understood. This article contributes to these open research questions. Building on theories of policy feedback, I argue that the accessibility of childcare provision shapes how attitudes towards maternal employment evolve. I expect an expansion of childcare provision to lead to more gender egalitarian attitudes towards maternal employment because it affects parents' opportunity structures to pursue paid work while their children are young, and because the availability of well-funded childcare should contribute to refute norms-based concerns that maternal employment could be harmful for child and family life. However, I expect the effect of expanding childcare provision to be highly contingent on the level of inequality in access to childcare provision.

In line with these expectations, the findings reveal that attitudes became more supportive of maternal employment between 2002 and 2012 in the sample of 18 European countries. Most importantly, however, the trend towards more egalitarian attitudes was more pronounced where access to childcare is more equal for parents across socio-economic backgrounds. Where inequality in childcare enrolment is low, attitude change towards more egalitarian attitudes was strongest among individuals in the lowest-income quintile. In contrast, with high inequality in childcare provision the lowest-income group revealed the most moderate development of more egalitarian attitudes. While the conditional effect of expanding childcare provision is evident across populations, the effects are most pronounced for women of childbearing age, who are most likely to be directly affected by changes in the accessibility of childcare provision.

The results have important implications for the politics of social investment, which should be addressed in future research. Changing attitudes towards maternal employment can crucially affect the feasibility and legitimacy of expansive childcare reforms. If lower-income families have limited access to childcare provision, this implies that they only benefit to a limited extent from expanding public spending on childcare provision. The difficulties lower-income families face in combining work and family life lead to lower levels of support for dual-earner arrangements, implying a more difficult political context in which to implement policies oriented towards facilitating the combination of work and family life.

Some questions remain for future research. This study has contributed to the literature by highlighting how inequality in childcare provision conditions the effects of expanding public childcare spending on attitudes towards maternal employment. Future work should widen this perspective and take into account, more than it has been possible to do in this article, the role of other factors potentially connected to the functioning of childcare services such as social policies, skill formation or the labour market (cf. León 2017). In addition, further investigation, which specific institutional characteristics of childcare provision are responsible for inequality in access (cf. Van Lancker and Ghysels 2016; Van Lancker 2018), and consequently for the unequal effects on attitudes, remains an important task. Ideally, such analyses would be complemented with panel data analyses. Finally, it would also be important to know to what extent the findings for attitudes towards maternal employment translate into actual support for expansive childcare reforms. Existing studies find an association between (women's) attitudes towards maternal employment and support for the government's role in childcare provision 
(e.g. Meuleman and Chung 2012), but it remains necessary to further specify for which individuals and in which contexts this relationship holds.

Supplementary material. To view supplementary material for this article, please visit https://doi.org/10. 1017/S0143814X19000333

Data Availability Statement. Replication materials are available in the Journal of Public Policy Dataverse at https://doi.org/10.7910/DVN/BQHIOP.

Acknowledgements. Previous versions of this article have been presented at the Conference of Europeanists in Glasgow in July 2017 and at various occasions at the University of Konstanz. I thank the participants, the editors of Journal of Public Policy, and the four anonymous reviewers for very helpful comments and suggestions. This work was supported by the European Research Council under Grant Number 311769.

\section{References}

Abou-Chadi T and Finnigan R (2019) Rights for Same-Sex Couples and Public Attitudes toward Gays and Lesbians in Europe. Comparative Political Studies, 52(6): 868-895.

Abrassart A and Bonoli G (2015) Availability, Cost or Culture? Obstacles to Childcare Services for Low Income Families. Journal of Social Policy, 44(4): 787-806.

Ball SJ and Nikita DP (2014) The Global Middle Class and School Choice: A Cosmopolitan Sociology. Zeitschrift für Erziehungswissenschaft, 17(3): 81-93.

Blome A (2017) The Politics of Work-Family Policy Reforms in Germany and Italy. London and New York: Routledge.

Bolzendahl C and Myers DJ (2004) Feminist Attitudes and Support for Gender Equality: Opinion Change in Women and Men, 1974-1998. Social Forces, 83(2): 759-790.

Brambor T, Clark WR and Golder M (2006) Understanding Interaction Models: Improving Empirical Analyses. Political Analysis, 14(1): 63-82.

Braun M and Scott J (2009) Changing Public Views of Gender Roles in Seven Nations: 1988-2002. In Haller M., Jowell R. and Smith T. W. (eds.), The International Social Survey Programme, 1984-2009 Charting the Globe. London and New York: Routledge, 358-377.

Busemeyer MR and Neimanns E (2017) Conflictive Preferences towards Social Investments and Transfers in Mature Welfare States: The Cases of Unemployment Benefits and Childcare Provision. Journal of European Social Policy, 27(3): 229-246.

Campbell AL (2012) Policy Makes Mass Politics. Annual Review of Political Science, 15: 333-351.

Cotter D, Hermsen JM and Vanneman R (2011) The End of the Gender Revolution? Gender Role Attitudes from 1977 to 2008. American Journal of Sociology, 117(1): 259-289.

Crompton R, Brockmann M and Lyonette C (2005) Attitudes, Women's Employment and the Domestic Division of Labour a Cross-National Analysis in Two Waves. Work, Employment \& Society, 19(2): 213-233.

Davis SN and Greenstein TN (2009) Gender Ideology: Components, Predictors, and Consequences. Annual Review of Sociology, 35: 87-105.

Ellingsæter AL and Gulbrandsen L (2007) Closing the Childcare Gap: The Interaction of Childcare Provision and Mothers' Agency in Norway. Journal of Social Policy, 36(4): 649-669.

Ellingsæter AL, Kitterød RH and Lyngstad J (2017) Universalising Childcare, Changing Mothers' Attitudes: Policy Feedback in Norway. Journal of Social Policy, 46(1): 149-173.

Esping-Andersen G (2002) Why We Need a New Welfare State. Oxford: Oxford University Press.

Fairbrother M (2014) Two Multilevel Modeling Techniques for Analyzing Comparative Longitudinal Survey Datasets. Political Science Research and Methods, 2(1): 119-140.

Gangl M and Ziefle A (2015) The Making of a Good Woman: Extended Parental Leave Entitlements and Mothers' Work Commitment in Germany. American Journal of Sociology, 121(2): 511-563.

Garritzmann JL, Häusermann S, Palier B and Zollinger C (2017) The World Politics of Social Investment. LIEPP Working Paper, no 64. 
Hegewisch A and Gornick JC (2011) The Impact of Work-Family Policies on Women's Employment: A Review of Research from OECD Countries. Community, Work \& Family, 14(2): 119-138.

Heisig JP and Schaeffer M (2019) Why You Should Always Include a Random Slope for the Lower-Level Variable Involved in a Cross-Level Interaction. European Sociological Review, 35(2): 258-279.

Hemerijck A (2013) Changing Welfare States. Oxford: Oxford University Press.

Hemerijck A (2015) The Quiet Paradigm Revolution of Social Investment. Social Politics: International Studies in Gender, State \& Society, 22(2): 242-256.

Hemerijck A (Ed.) (2017) The Uses of Social Investment. Oxford: Oxford University Press.

Hogrebe N (2016) Choice and Equal Access in Early Childhood Education and Care: The Case of Germany. ICMEC International Seminar Series Working Paper No. 1. International Centre for the Study of the Mixed Economy of Childcare. UEL's Cass School of Education and Communities.

ISSP (2002) International Social Survey Programme: Family and Changing Gender Roles III.

ISSP (2012) International Social Survey Programme: Family and Changing Gender Roles IV.

Kangas $\mathbf{O}$ and Rostgaard T (2007) Preferences or Institutions? Work - Family Life Opportunities in Seven European Countries. Journal of European Social Policy, 17(3): 240-256.

Knudsen K and Wærness K (2001) National Context, Individual Characteristics and Attitudes on Mothers' Employment: A Comparative Analysis of Great Britain, Sweden and Norway. Acta Sociologica, 44(1): 67-79.

Korpi W, Ferrarini T and Englund S (2013) Women's Opportunities under Different Family Policy Constellations: Gender, Class, and Inequality Tradeoffs in Western Countries Re-examined. Social Politics: International Studies in Gender, State \& Society, 20(1): 1-40.

Kowalewska H (2017) Beyond the "Train-First"/“Work-First" Dichotomy: How Welfare States Help or Hinder Maternal Employment. Journal of European Social Policy, 27(1): 3-24.

Kumlin S and Stadelmann-Steffen I (2014) Citizens, Policy Feedback, and European Welfare States. In Kumlin S and Stadelmann-Steffen I (eds.), How Welfare States Shape the Democratic Public: Policy Feedback, Participation, Voting, and Attitudes. Cheltenham: Edward Elgar Publishing, 3-18.

León M (2017) Social Investment and Childcare Expansion: A Perfect Match? In Hemerijck A. (ed.), The Uses of Social Investment. Oxford: Oxford University Press, 118-127.

Lewis J, Campbell M and Huerta C (2008) Patterns of Paid and Unpaid Work in Western Europe: Gender, Commodification, Preferences and the Implications for Policy. Journal of European Social Policy, 18(1): 21-37.

McRae S (1993) Returning to Work after Childbirth: Opportunities and Inequalities. European Sociological Review, 9(2): 125-138.

Mettler S and Soss J (2004) The Consequences of Public Policy for Democratic Citizenship: Bridging Policy Studies and Mass Politics. Perspectives on Politics, 2(1): 55-73.

Meuleman B and Chung H (2012) Who Should Care for the Children? Support for Government Intervention in Childcare. In Ervasti H., Andersen J. G., Fridberg T. and Ringdal K. (eds.), The Future of the Welfare State: Social Policy Attitudes and Social Capital in Europe. Cheltenham: Edward Elgar, 107-133.

Morel N, Palier B and Palme J (Ed.) (2012) Towards a Social Investment Welfare State? Bristol: The Policy Press.

Morgan KJ (2006) Working Mothers and the Welfare State: Religion and the Politics of Work-Family Policies in Western Europe and the United States. Stanford: Stanford University Press.

Morgan KJ (2013) Path Shifting of the Welfare State: Electoral Competition and the Expansion of Work-Family Policies in Western Europe. World politics, 65(1): 73-115.

OECD (2017) OECD Family Database, www.oecd.org/social/family/database.htm (accessed 01 June 2018).

Pavolini E and Van Lancker W (2018) The Matthew Effect in Childcare Use: A Matter of Policies or Preferences? Journal of European Public Policy, 25(6): 878-893.

Pedulla DS and Thébaud S (2015) Can We Finish the Revolution? Gender, Work-Family Ideals, and Institutional Constraint. American Sociological Review, 80(1): 116-139.

Penn H (2013) Childcare Markets: Do they Work? In Lloyd E. and Penn H. (eds.), Childcare Markets Can they Deliver an Equitable Service? Bristol: Policy Press, 19-42.

Pierson P (1993) When Effect Becomes Cause. World Politics, 45(4): 595-628.

Schneider A and Ingram H (1993) Social Construction of Target Populations: Implications for Politics and Policy. American Political Science Review, 87(2): 334-347. 
Schober P and Scott J (2012) Maternal Employment and Gender Role Attitudes: Dissonance among British Men and Women in the Transition to Parenthood. Work, Employment and Society, 26(3): 514-530.

Schwander H (2018) Electoral Demand, Party Competition, and Family Policy: The Politics of a New Policy Field. In Manow P., Palier B. and Schwander H. (eds.), Welfare Democracies and Party Politics: Explaining Electoral Dynamics in Times of Changing Welfare Capitalism. Oxford: Oxford University Press, 197-224.

Sjöberg O (2004) The Role of Family Policy Institutions in Explaining Gender-Role Attitudes: A Comparative Multilevel Analysis of Thirteen Industrialized Countries. Journal of European Social Policy, 14(2): 107-123.

Soss J and Schram SF (2007) A Public Transformed? Welfare Reform as Policy Feedback. American Political Science Review, 101(1):111-127.

Unterhofer U and Wrohlich K (2017) Fathers, Parental Leave and Gender Norms. IZA Discussion Paper, No. 10712.

Van Lancker W (2013) Putting the Child-Centred Investment Strategy to the Test: Evidence for the EU27. European Journal of Social Security, 15(1): 4-27.

Van Lancker W (2018) Reducing Inequality in Childcare Service Use across European Countries: What (If Any) Is the Role of Social Spending? Social Policy \& Administration, 52(1): 271-292.

Van Lancker W and Ghysels J (2012) Who Benefits? The Social Distribution of Subsidized Childcare in Sweden and Flanders. Acta Sociologica, 55(2): 125-142.

Van Lancker W and Ghysels J (2016) Explaining Patterns of Inequality in Childcare Service Use across 31 Developed Economies: A Welfare State Perspective. International Journal of Comparative Sociology, 57(5): 310-337.

Zoch G and Schober PS (2018) Public Child-Care Expansion and Changing Gender Ideologies of Parents in Germany. Journal of Marriage and Family, 80(4): 1020-1039.

Cite this article: Neimanns E (2021). Unequal benefits - diverging attitudes? Analysing the effects of an unequal expansion of childcare provision on attitudes towards maternal employment across 18 European countries. Journal of Public Policy 41, 251-276. https://doi.org/10.1017/S0143814X19000333 